\title{
A UTILIZAÇÃo dE TEORIAS EM ESTUDOS ORGANIZACIONAIS BRASILEIROS: UMA ANÁLISE BIBLIOMÉTRICA
}

THE USE OF THEORIES IN BRAZILIAN ORGANIZATIONAL STUDIES: A BIBLIOMETRIC ANALYSIS

Flavio Perazzo Barbosa Mota (fmota@yahoo.com)

\section{CERES GREHS BECK}

\section{Rita de CÁssia de Faria Pereira}

Tatiana Aguiar Porfírio de Lima

SOLANGE CRISTINA do VALE

UNIVERSIDADE FEDERAL DA PARAÍBA

\section{RESUMO}

As teorias procuram explicar de forma sistemática fatos e acontecimentos, permitindo resumir o conhecimento e favorecer a manutenção ou modificação do entendimento das práticas organizacionais. O objetivo deste artigo é levantar e analisar a base teórica nas publicações científicas voltadas à explicação de fenômenos organizacionais, de modo a identificar a utilização - ou não - de teorias em Estudos Organizacionais, bem como analisar os aspectos metodológicos adotados. Para tanto, foi realizado um levantamento bibliográfico dos cento e cinquenta artigos acadêmicos apresentados no Encontro Nacional dos Programas de PósGraduação em Administração (EnANPAD), no período de 2005 a 2008. Os dados e teorias identificados foram tabulados, classificados e analisados. Constatou-se que mais da metade dos artigos (54,7\%) utilizam teorias. Houve um predomínio de utilização da Teoria Institucional (24,1\%), seguida da Teoria da Estruturação (7,8\%), Teoria das Representações Sociais (4,3\%), Teoria Crítica (3,4\%), Teoria da Agência (3,4\%) e Teoria dos Custos de Transação (3,4\%). Logo, percebe-se a falta de inserção do Brasil como desenvolvedor de teorias, ou seja, há mais uma replicação de teorias consolidadas internacionalmente, do que propriamente inovação teórica no contexto brasileiro. Ademais, prevaleceram a produção em coautoria, a estratégia de pesquisa qualitativa e a natureza empírica.

Palavras-chave: estudos organizacionais; teorias; levantamento bibliográfico. 


\section{ABSTRACT}

Theories in Brazilian Organizational Studies aim to systematically explain facts and events, allowing knowledge to be summarized and facilitating the preservation or modification of the understanding of organizational practices. The objective of this paper is to survey and analyze the theoretical foundations of scientific papers investigating organizational phenomena in order to identify whether or not theories are being used in Organizational Studies, as well as to analyze the adopted methodological aspects. This is achieved through the desk research of the one hundred and fifty academic articles submitted to EnANPAD, for the period 2005-2008. The subsequently identified data and theory is classified and analyzed, with results reporting that more than half of the studies analyzed (54.7\%) used theories. The use of Institutional Theory (24.1\%) is predominant, followed by Structuration Theory (7.8\%), Theory of Social Representations (4.3\%), Critical Theory (3.4\%), Agency Theory (3.4\%) and Transactions Cost Theory (3.4\%). It is soon apparent that Brazil has yet to appear as a source of theories, that is, it is much more common to see the use of internationally consolidated theories than any actual theoretical innovation within the Brazilian context. Furthermore, co-authorship, qualitative research strategy and the empirical nature were identified.

Keywords: organizational studies; theories; desk research.

\section{INTRODUÇÃO}

O campo de pesquisas em Administração, no Brasil, vem apresentando crescimento na quantidade de publicações acadêmicas (ROSSONI et al., 2007). A evolução da produção científica tem sido investigada por meio de análises longitudinais, abrangendo as áreas de Organizações (MACHADO-DA-SILVA; CUNHA; AMBONI, 1990; BERTERO; KEINERT, 1994; VERGARA; PINTO, 2001), marketing (VIEIRA, 1998; RÉVILLION, 2001; KOVACS et al., 2004; ALMEIDA; LOPES; PEREIRA, 2006; FARIA et al., 2006), estratégia empresarial (BERTERO; VASCONCELOS; BINDER, 2003; GRZEBIELUCKAS et al., 2008; WALTER; SILVA, 2008), sistemas de informações (HOPPEN; MEIRELLES, 2005) e contabilidade (CARDOSO; PEREIRA; GUERREIRO, 2003). 
Machado-da-Silva, Cunha e Amboni (1990) desenvolveram um trabalho pioneiro avaliando os artigos da área de Organizações e diagnosticaram uma fragilidade teórico-metodológica na produção científica na área, bem como o predomínio de uma abordagem funcionalista. Os principais resultados apontaram para a multidisciplinaridade das variáveis de estudo, oriundas de diferentes áreas do conhecimento, como a sociologia, psicologia, ciência política e comunicação. Além disso, os autores concluíram que a produção científica priorizou a repetição e divulgação de ideias desenvolvidas por escolas estrangeiras, principalmente estadunidenses, com trabalhos centrados em reflexões e elaborações teóricas sem aplicação prática. Outra contribuição importante foi realizada no estudo de Bertero e Keinert (1994), que avaliaram a evolução da pesquisa acadêmica brasileira em Análise Organizacional entre 1961 e 1993, dando ênfase às escolas ou perspectivas teóricas mais significativas.

A partir disso, percebe-se a necessidade de constante reflexão sobre o conhecimento produzido no contexto brasileiro. Assim, tendo em vista que "a teoria é a finalidade da investigação científica" (SAMPIERI; COLLADO; LUCIO, 1994, p. 41) e que "a função mais importante de uma teoria é explicar: dizer o porquê, como e quando ocorre um fenômeno" (SAMPIERI; COLLADO; LUCIO, 2006, p. 72), surge o questionamento sobre quais teorias vêm sendo aplicadas na produção científica brasileira para explicação de fenômenos na área temática de Teoria das Organizações. Parte-se da premissa que o saber em forma de teoria representa um fato aceitável, com uma compreensão adequada e que assegura maior validade à construção do conhecimento científico (LAVILLE; DIONNE, 1997).

Neste sentido, o objetivo deste artigo é levantar e analisar a base teórica nas publicações científicas voltadas à explicação de fenômenos organizacionais, na tentativa de preencher uma lacuna identificada nos trabalhos bibliográficos sobre a utilização de teorias associadas aos estudos organizacionais. Ademais, foram consideradas outras categorias relacionadas ao método para a análise dos artigos selecionados, tais como: ano de publicação, número de autores, estratégia e natureza de pesquisa.

Diante da relevância da utilização de teorias e da necessidade de constantemente reavaliar o campo de conhecimento em Administração, foi selecionada a área temática de Teoria das Organizações (EOR-A) do Encontro Anual da Associação Nacional dos Programas de PósGraduação em Administração (EnANPAD) e foram avaliados os artigos publicados entre anos de 2005 a 2008. 
Este artigo está organizado em três partes, sendo a primeira composta desta introdução enquanto, na segunda parte, os procedimentos metodológicos adotados são descritos. Por fim, é apresentado o referencial teórico e são discutidos os resultados encontrados. Assim, nesta parte, são efetuadas as considerações decorrentes das interpretações que são corroboradas com base nas referências conceituais.

\section{Procedimentos Metodológicos}

Este estudo é considerado um trabalho bibliométrico, ou seja, de revisão e levantamento bibliográfico da produção acadêmica do tema relacionado às teorias em Estudos Organizacionais Brasileiros publicados $\mathrm{e}$ apresentados no Encontro Anual da Associação Nacional dos Programas de Pós-Graduação em Administração (EnANPAD), no período de quatro anos, compreendido entre 2005 a 2008. Este evento foi selecionado devido a sua representatividade no cenário nacional ao longo de edições regulares nos últimos trinta e dois anos e, também, porque reúne grande parte do esforço de pesquisa científica no Brasil. A Divisão Acadêmica de Estudos Organizacionais foi estabelecida pela primeira vez na ANPAD a partir de 2005, justificando-se, portanto, o início da pesquisa a partir deste ano. Dentro desta divisão acadêmica, composta por três áreas (EOR-A, EOR-B e EOR-C), a área temática escolhida foi Teoria das Organizações (EOR-A), conforme detalhado no Quadro 1.

Quadro 1: Divisão de artigos de Estudos Organizacionais no EnANPAD

\begin{tabular}{l}
\hline Áreas Temáticas da EOR - Estudos Organizacionais \\
\hline EOR-A - Teoria das Organizações \\
\hline EOR-B - Comportamento Organizacional \\
\hline EOR-C - Teoria Crítica em Estudos Organizacionais
\end{tabular}

Fonte: ANPAD (2008a).

A escolha da área de Teoria das Organizações (EOR-A) como objeto de investigação ocorreu justamente por coincidir o interesse desta pesquisa com o objetivo declarado e especificado pela ANPAD na descrição desta área temática:

Esta Área caracteriza-se por atividades na investigação de fenômenos organizacionais e sociais, procurando construir interfaces entre as áreas da Teoria Organizacional e o Pensamento Social. Abrange trabalhos teóricos, empíricos e ensaios sobre as organizações, oriundos de diferentes perspectivas epistemológicas, teóricas e metodológicas. Preocupa-se em evidenciar a diversidade 
dos estudos organizacionais na realidade brasileira, ao mesmo tempo em que busca corroborar com a crítica e a (re)avaliação constante dos estudos desenvolvidos na própria Área. Neste sentido, além de temas considerados clássicos, a Área busca também proporcionar uma reflexão sobre características e peculiaridades de algumas novas perspectivas contemporâneas em análise organizacional. Sugerem-se, como linhas temáticas, trabalhos que discutam novas formas de gestão, velho e novo institucionalismo, simbolismo organizacional, particularizando questões de cultura nas organizações, identidade organizacional, organizações familiares, indústria criativa, formas de controle nas organizações e na sociedade organizacional, poder e resistência nas organizações, cooperação e confiança organizacional, entre outras (ANPAD, 2008b).

Foram classificados todos os cento e cinquenta artigos apresentados nos anos de 2005 a 2008 na área EOR-A (Tabela 1). As etapas da pesquisa consistiram em: (1) definição das categorias de análise, a saber: ano de publicação, número de autores, estratégia e natureza de pesquisa e, principalmente, a(s) teoria(s) utilizada(s), (2) leitura dos artigos, (3) identificação e classificação dos dados obtidos conforme as categorias definidas, (4) tabulação dos dados, e (5) análise dos resultados. Cada etapa foi executada pelos cinco autores deste artigo.

Tabela 1: Distribuição de artigos por ano - Área Temática EOR-A (Teoria das Organizações)

\begin{tabular}{ccc}
\hline Ano & $\begin{array}{c}\text { Quantidade de } \\
\text { artigos }\end{array}$ & $\begin{array}{c}\text { Percentual do } \\
\text { total }\end{array}$ \\
\hline 2005 & 34 & $22,7 \%$ \\
\hline 2006 & 33 & $22 \%$ \\
\hline 2007 & 41 & $27,3 \%$ \\
\hline 2008 & 42 & $28 \%$ \\
\hline Total & $\mathbf{1 5 0}$ & $\mathbf{1 0 0 \%}$ \\
\hline
\end{tabular}

$\mathrm{Na}$ etapa de análise, embora a mediana do total de teorias identificadas tenha indicado que a utilização de teoria em cinco ou mais artigos seria o critério de corte a ser utilizado, decidiu-se que, para definição da representatividade de cada teoria, o mínimo seriam quatro artigos. Este corte permitiu melhor exploração das correntes teóricas identificadas, ampliando o detalhamento para as seis teorias mais utilizadas nos artigos analisados. As demais teorias que não se enquadraram nesta regra formulada pelos pesquisadores foram 
categorizadas como Teorias Diversas. No caso da ocorrência de um artigo utilizar mais de uma teoria para explicação do fenômeno organizacional em questão, contabilizou-se cada uma de forma individual. Outro fato que merece destaque é que não foi identificada uma quantidade representativa de teorias utilizadas conjuntamente, razão pela qual se decidiu por não fazer este tipo de análise separadamente, e eventualmente, quando isso ocorria, estas teorias eram analisadas separadamente.

Os dados foram tabulados com o auxílio dos softwares Microsoft Excel 2003 e SPSS (Statistical Package for the Social Sciences) 15.0. A partir disto foram realizadas análises cruzadas, que, conforme Malhotra (2001, p. 408), refletem "a distribuição conjunta de duas ou mais variáveis com um número limitado de categorias ou valores distintos”.

\section{ANÁlise E Discussão dos RESUltados}

Com base nos procedimentos metodológicos descritos, são apresentadas, primeiramente, as análises dos resultados acerca dos aspectos relacionados aos métodos aplicados nos artigos para, em seguida, proceder à apreciação da utilização ou não de teorias nos artigos em estudo. Complementando a análise, são referenciadas conjuntamente as bases teóricas que buscam explicar os resultados que emergiram da pesquisa.

\section{Distribuição do número de autores por artigos}

Analisando o número de publicações com dois ou mais autores nos anos pesquisados, é possível constatar que a coautoria é uma prática frequente dentro da área temática de Teoria das Organizações, com $70 \%$ da produção acadêmica desenvolvida desta forma. Estes percentuais mais significativos estão grifados na Tabela 2 .

Tabela 2: Número de autores por artigos

\begin{tabular}{|c|c|c|c|c|c|c|c|c|c|c|}
\hline \multirow{3}{*}{$\begin{array}{l}\text { Número } \\
\text { de } \\
\text { Autores }\end{array}$} & \multicolumn{10}{|c|}{ EnANPAD (EOR-A) } \\
\hline & \multicolumn{2}{|c|}{2005} & \multicolumn{2}{|c|}{2006} & \multicolumn{2}{|c|}{2007} & \multicolumn{2}{|c|}{2008} & \multicolumn{2}{|c|}{ Total } \\
\hline & $\mathrm{N}$ & Freq. & $\mathrm{N}$ & Freq. & $\mathrm{N}$ & Freq. & $\mathrm{N}$ & Freq. & $\mathrm{N}$ & Freq. \\
\hline 1 & 14 & $9,3 \%$ & 9 & $6 \%$ & 13 & $8,7 \%$ & 9 & $6 \%$ & 45 & $30 \%$ \\
\hline 2 & 16 & $10,7 \%$ & 14 & $9,3 \%$ & 18 & $12 \%$ & 17 & $11,3 \%$ & 65 & $43,3 \%$ \\
\hline 3 & 2 & $1,3 \%$ & 7 & $4,7 \%$ & 9 & $6 \%$ & 10 & $6,7 \%$ & 28 & $18,7 \%$ \\
\hline 4 & 2 & $1,3 \%$ & 2 & $1,3 \%$ & 1 & $0,7 \%$ & 6 & $4 \%$ & 11 & $7,3 \%$ \\
\hline 5 & 0 & - & 1 & $0,7 \%$ & 0 & - & 0 & - & 1 & $0,7 \%$ \\
\hline Total & 34 & $22,7 \%$ & 33 & $22 \%$ & 41 & $27,3 \%$ & 42 & $28 \%$ & 150 & $100 \%$ \\
\hline
\end{tabular}


De acordo com Bertero, Vasconcelos e Binder (2003), o desenvolvimento de artigos em coautoria pode ser explicado pela pressão crescente por publicar, advinda de decisões dos órgãos de avaliação de programas strictu sensu, como CAPES e CNPq, bem como pelo aumento dos grupos de pesquisa criados nos diversos programas de pós-graduação brasileiros que estimulam a produção em parceria entre professores e alunos.

Estudos anteriores similares nas áreas de estratégia (BERTERO; VASCONCELOS; BINDER, 2003; ROSSONI et al., 2007), contabilidade (CARDOSO; PEREIRA; GUERREIRO, 2003) e marketing (ALMEIDA; LOPES; PEREIRA, 2006; KOVACS et al., 2004; VIEIRA, 1998), também constataram crescimento gradual de cooperação de autores.

Os números apresentados na Tabela 2, entretanto, não permitem avaliar se há continuidade ou diversificação de atuantes na área, visto que a investigação dessas causas não foi objeto deste estudo.

\section{Definição da estratégia e natureza de pesquisa}

Toda pesquisa científica requer um rigor metodológico, de forma a assegurar a confiabilidade dos seus resultados (LAVILLE; DIONNE, 1997). Quanto à estratégia, os estudos científicos podem ser categorizados em quantitativos e qualitativos, cabendo ao pesquisador adaptar o método escolhido ao seu problema de pesquisa (GUNTHER, 2006). Neste ínterim, ressalte-se que, quando se faz uma revisão de literatura sobre estratégias de pesquisa, observa-se que, frequentemente, não é possível encontrar uma definição por si só do que seja a pesquisa qualitativa. É mais comum a referência a esta estratégia de pesquisa como contraponto à quantitativa (GUNTHER, 2006; FLICK, 2004).

Segundo Gunther (2006), a abordagem qualitativa estuda o fenômeno no seu contexto natural, com uma relativa falta de controle das variáveis, considerando todas importantes; já a abordagem quantitativa implica em pesquisas que tentam obter um controle máximo sobre o contexto, reduzindo ou eliminando variáveis irrelevantes. Na Tabela 3 são apresentados os resultados obtidos em relação às estratégias de pesquisa mais utilizadas. 
Tabela 3: Estratégia de pesquisa

\begin{tabular}{cccccccccccc}
\hline \multirow{2}{*}{$\begin{array}{c}\text { Estratégia } \\
\text { de Pesquisa }\end{array}$} & \multicolumn{10}{c}{ EnANPAD (EOR-A) } \\
\cline { 2 - 13 } & $\mathbf{2 0 0 5}$ & $\mathbf{2}$ & Freq. & $\mathrm{N}$ & Freq. & $\mathrm{N}$ & Freq. & $\mathrm{N}$ & Freq. & $\mathrm{N}$ & Freq. \\
\hline Qualitativa & 32 & $21,3 \%$ & 31 & $20,7 \%$ & 37 & $24,7 \%$ & 37 & $24,7 \%$ & 137 & $\mathbf{9 1 , 3 \%}$ \\
\hline Quantitativa & 2 & $1,3 \%$ & 2 & $1,3 \%$ & 3 & $2 \%$ & 4 & $2,7 \%$ & 11 & $7,3 \%$ \\
\hline $\begin{array}{c}\text { Quanti- } \\
\text { qualitativa }\end{array}$ & 0 & - & 0 & - & 1 & $0,7 \%$ & 1 & $0,7 \%$ & 2 & $1,3 \%$ \\
\hline Total & $\mathbf{3 4}$ & $22,7 \%$ & $\mathbf{3 3}$ & $22 \%$ & $\mathbf{4 1}$ & $27,3 \%$ & $\mathbf{4 2}$ & $28 \%$ & $\mathbf{1 5 0}$ & $100 \%$ \\
\hline
\end{tabular}

Com base nos dados da Tabela 3, infere-se que a estratégia de pesquisa mais utilizada na área temática de Teoria das Organizações foi a qualitativa, atingindo a cifra de 91,3\%. Tais resultados vão ao encontro dos achados na área de estratégia (BERTERO; VASCONCELOS; BINDER, 2003; ROSSONI et al., 2007), em que também há um predomínio de estudos qualitativos. Já, nas áreas de marketing (KOVACS et al., 2004; ALMEIDA; LOPES; PEREIRA, 2006) e contabilidade (CARDOSO; PEREIRA; GUERREIRO, 2003) têm sobressaído pesquisas quantitativas.

Tabela 4: Natureza de Pesquisa

\begin{tabular}{|c|c|c|c|c|c|c|c|c|c|c|}
\hline \multirow{3}{*}{$\begin{array}{l}\text { Natureza de } \\
\text { Pesquisa }\end{array}$} & \multicolumn{10}{|c|}{ EnANPAD (EOR-A) } \\
\hline & \multicolumn{2}{|c|}{2005} & \multicolumn{2}{|c|}{2006} & \multicolumn{2}{|c|}{2007} & \multicolumn{2}{|c|}{2008} & \multicolumn{2}{|c|}{ Total } \\
\hline & $\mathrm{N}$ & Freq. & $\mathrm{N}$ & Freq. & $\mathrm{N}$ & Freq. & $\mathrm{N}$ & Freq. & $\mathrm{N}$ & Freq. \\
\hline $\begin{array}{l}\text { Teórica- } \\
\text { Empírica }\end{array}$ & 22 & $14,7 \%$ & 21 & $14 \%$ & 25 & $16,7 \%$ & 30 & $20 \%$ & 98 & $65,3 \%$ \\
\hline Teórica & 12 & $8 \%$ & 12 & $8 \%$ & 16 & $10,7 \%$ & 12 & $8 \%$ & 52 & $34,7 \%$ \\
\hline Total & 34 & $22,7 \%$ & 33 & $22 \%$ & 41 & $27,3 \%$ & 42 & $28 \%$ & 150 & $100 \%$ \\
\hline
\end{tabular}

No que se refere à natureza de pesquisa, os artigos foram classificados em teóricos ou teórico-empíricos. Baseado na análise da Tabela 4 é possível perceber que as pesquisas de natureza teóricoempírica predominam dentro da área de Teoria das Organizações (65,3\%), embora as puramente teóricas apresentem uma quantidade significativa (34,7\%). Este resultado é semelhante ao encontrado em outras áreas, como em Administração Estratégica, em que Rossoni et al. (2007) constataram que $83 \%$ das produções analisadas no período entre 2003 a 2006 eram teórico-empíricas.

Os resultados apresentados nas Tabelas 3 e 4 permitem concluir que a área de Teoria das Organizações do EnANPAD prioriza a publicação de artigos dentro de uma perspectiva qualitativa e de natureza teórico-empírica. 


\section{TEORIAS}

Para Sampieri, Collado e Lucio (1994, 2006), a teoria consiste de um conjunto de conceitos, proposições e definições relacionadas entre si, capazes de explicar sistematicamente como um determinado fenômeno ocorre em um ambiente. Sutton e Staw (1995) constatam que existe pouca concordância sobre o que é teoria; mas, o consenso é que referências, dados, variáveis, diagramas e hipóteses não são teorias. Marconi e Lakatos (2006), por sua vez, argumentam que as teorias podem ser entendidas como ideias não consumadas, dependentes de verificação para tornarem-se verdadeiras. Tal argumento é corroborado por Laville e Dionne (1997) ao afirmarem que o conhecimento mantém-se inalterado até sua contestação por outras interpretações. Entende-se, assim, que as teorias não são estáticas e imutáveis ao longo do tempo, mas compreendem versões ou perspectivas por meio das quais o mundo é visto (FLICK, 2004).

Considera-se que a construção de uma teoria envolve o questionamento acerca de novas abordagens e mudanças na prática da ciência (WHETTEN, 2003). Parte-se da premissa que uma teoria deve oferecer um sistema de conceitos e de classificação dos fatos, permitindo resumir o conhecimento, sintetizando o que já é conhecido sobre o objeto de estudo. Tem-se ainda que, por meio de seus pressupostos, uma teoria serve também para prever novos fatos e relações, ultrapassando as observações imediatas e o senso comum. Ademais, indica lacunas de conhecimento, possibilitando trabalhar com fatos e relações que não foram totalmente explicadas e onde há carência de pesquisas (MARCONI; LAKATOS, 2006).

Assim, pode-se entender que as teorias são elementos importantes na construção de novos conhecimentos, sendo possível aceitar que estas sejam uma compreensão adequada e não perene da realidade, ou seja, outras verificações podem ser capazes de, em outros momentos, reforçar sua validade (LAVILLE; DIONNE, 1997). Além do seu aspecto evolutivo, a teoria tem como propósito orientar a abrangência dos fatos a serem estudados (MARCONI; LAKATOS, 2006), definindo os principais aspectos de uma investigação, bem como os tipos de dados a serem abstraídos da realidade como objeto de análise. Diante destes esclarecimentos acerca do que consistem as teorias, percebe-se a necessidade de constantemente reavaliar o campo de conhecimento em Administração. 
Baseado no entendimento sobre o conceito de teoria, foi feita uma análise dos artigos pesquisados de forma a identificar quais se fundamentam em uma ou mais teorias para explicar os fenômenos organizacionais no mundo contemporâneo, conforme evidenciado pelos resultados expostos na Tabela 5.

Tabela 5: Utilização ou não de teorias

\begin{tabular}{|c|c|c|c|c|c|c|c|c|c|c|}
\hline \multirow{3}{*}{$\begin{array}{l}\text { Utiliza } \\
\text { Teoria? }\end{array}$} & \multicolumn{10}{|c|}{ EnANPAD (EOR-A) } \\
\hline & \multicolumn{2}{|c|}{2005} & \multicolumn{2}{|c|}{2006} & \multicolumn{2}{|c|}{2007} & \multicolumn{2}{|c|}{2008} & \multicolumn{2}{|c|}{ Total } \\
\hline & $\mathrm{N}$ & Freq. & $\mathrm{N}$ & Freq. & $\mathrm{N}$ & Freq. & $\mathrm{N}$ & Freq. & $\mathrm{N}$ & Freq. \\
\hline Não & 18 & $12 \%$ & 12 & $8 \%$ & 18 & $12 \%$ & 20 & $13,3 \%$ & 68 & $45,3 \%$ \\
\hline Sim & 16 & 10,7 & 21 & $14 \%$ & 23 & $15,3 \%$ & 22 & $14,7 \%$ & 82 & $54,7 \%$ \\
\hline Total & 34 & 22,7 & 33 & $22 \%$ & 41 & $27,3 \%$ & 42 & $28 \%$ & 150 & $100 \%$ \\
\hline
\end{tabular}

Constatou-se que muitos artigos (45,3\%) não se utilizam de teorias para embasar a explicação dos fenômenos organizacionais, mas, sim, constroem o referencial teórico com base em modelos, hipóteses e referências, os quais não podem ser enquadrados como teoria, segundo a definição de Sutton e Staw (1995). De fato, na maioria dos artigos que não indicam um marco teórico, não foram identificados indícios de referências a uma teoria, já que os fundamentos utilizados não atendem os itens apontados por Whetten (2003) como essenciais na definição do que é uma teoria, a saber: o questionamento acerca de novidades, novas abordagens e mudanças na prática da ciência na área. Por outro lado, identificou-se que $54,7 \%$ dos artigos analisados utilizam de alguma teoria para explicar ou embasar o conhecimento.

Vale salientar que a análise das publicações do EnANPAD no período referido não possibilita estabelecer conclusões acerca de tendências de crescimento ou declínio no uso de teorias.

\section{TEORIAS ORgANIZACIONAIS}

De acordo com Caldas e Fachin (2005), a partir de 1980 houve um crescimento acelerado na área de estudos organizacionais. Esta assertiva se ratifica a partir de trabalhos como os de Machado-da-Silva, Cunha e Amboni (1990), Bertero e Keinert (1994) e Vergara e Pinto (2001). O interesse pela compreensão dos fenômenos organizacionais tem sido analisado sobre diversas perspectivas, podendo-se relacionar desde o início do pensamento administrativo, passando pelos paradigmas sociológicos propostos por Burrell e Morgan (1979) até as reflexões 
atuais. Este empenho reflete-se no esforço de Caldas e Bertero (2007), que buscaram retratar o estado-da-arte do campo no fim do século XX e início do século XXI, dada a preocupação manifestada por Caldas (2005) em relação às deficiências dos estudos em Teoria das Organizações no Brasil.

De acordo com Astley e Van de Ven (2005), a teoria das organizações não reflete apenas a realidade organizacional, mas também produz essa realidade. Os autores ainda afirmam que a interação entre as teorias organizacionais resulta, por assim dizer, em uma disputa pela futura formação do ambiente organizacional e é preciso ter consciência das tendências e valores sobre os quais se constrói a teoria.

Logo, resgatando o objetivo deste trabalho, que é o de levantar e analisar a base teórica nas publicações científicas voltadas à explicação de fenômenos organizacionais, na tentativa de preencher uma lacuna identificada nos trabalhos bibliográficos sobre a utilização de teorias associadas aos estudos organizacionais, apresentam-se as seis teorias mais citadas na Tabela 6. A tabulação dos dados seguiu o corte definido pelos autores, ou seja, que uma teoria deveria estar presente em quatro ou mais artigos.

Tabela 6: Teorias Utilizadas

\begin{tabular}{|c|c|c|c|c|c|c|c|c|c|c|}
\hline \multirow{3}{*}{ Teoria } & \multicolumn{10}{|c|}{ EnANPAD (EOR-A) } \\
\hline & \multicolumn{2}{|c|}{2005} & \multicolumn{2}{|c|}{2006} & \multicolumn{2}{|c|}{2007} & \multicolumn{2}{|c|}{2008} & \multicolumn{2}{|c|}{ Total } \\
\hline & $\mathrm{N}$ & Freq. & $\mathrm{N}$ & Freq. & $\mathrm{N}$ & Freq. & $\mathrm{N}$ & Freq. & $\mathrm{N}$ & Freq. \\
\hline $\begin{array}{l}\text { 1. Teoria } \\
\text { Institucional }\end{array}$ & 6 & $25 \%$ & 7 & $30,4 \%$ & 7 & $17,1 \%$ & 8 & $28,6 \%$ & 28 & $24,1 \%$ \\
\hline $\begin{array}{l}\text { 2. Teoria da } \\
\text { Estruturação }\end{array}$ & 2 & $8,3 \%$ & 1 & $4,3 \%$ & 4 & $9,8 \%$ & 2 & $7,1 \%$ & 9 & $7,8 \%$ \\
\hline $\begin{array}{l}\text { 3. Teoria das } \\
\text { Representações } \\
\text { Sociais }\end{array}$ & 0 & 0 & 2 & $8,7 \%$ & 0 & 0 & 3 & $10,7 \%$ & 5 & $4,3 \%$ \\
\hline $\begin{array}{l}\text { 4. Teoria } \\
\text { Crítica }\end{array}$ & 3 & $12,5 \%$ & 0 & 0 & 0 & 0 & 1 & $3,6 \%$ & 4 & $3,4 \%$ \\
\hline $\begin{array}{l}\text { 5. Teoria da } \\
\text { Agência }\end{array}$ & 1 & $4,2 \%$ & 0 & 0 & 1 & $2,4 \%$ & 2 & $7,1 \%$ & 4 & $3,4 \%$ \\
\hline $\begin{array}{l}\text { 6. Teoria dos } \\
\text { Custos de } \\
\text { Transação }\end{array}$ & 0 & 0 & 1 & $4,3 \%$ & 1 & $2,4 \%$ & 2 & $7,1 \%$ & 4 & $3,4 \%$ \\
\hline $\begin{array}{l}\text { Teorias } \\
\text { Diversas } \\
\end{array}$ & 12 & $50 \%$ & 12 & $52,2 \%$ & 28 & $68,3 \%$ & 10 & $35,7 \%$ & 62 & $53,4 \%$ \\
\hline Total & 24 & $100 \%$ & 23 & $100 \%$ & 41 & $100 \%$ & 28 & $100 \%$ & 116 & $100 \%$ \\
\hline
\end{tabular}


Conforme os dados apresentados na Tabela 5, destaca-se que, das oitenta e duas publicações $(54,7 \%)$ que utilizam uma ou mais teorias, foram identificadas seis correntes teóricas de maior representatividade.

É importante mencionar que na categoria Teorias Diversas, foram encontradas algumas teorias consolidadas internacionalmente e que foram aplicadas, contudo, em menos de quatro artigos. Pode-se citar, entre outras, a Teoria do Campo Social, a Teoria dos Stakeholders, a Teoria da Firma, a Teoria dos Jogos, a Teoria da Contingência e a Teoria da Dependência de Recursos. A alta representatividade desta categoria corrobora o que apontam Astley e Van de Ven (2005, p. 53), ou seja, a percepção de um "pluralismo teórico na literatura organizacional em teoria das organizações”, explicado tanto pelo crescimento da conscientização da complexidade das organizações como pelo apuramento dos interesses e das inquietações dos teóricos a seu respeito. Os autores complementam que, ao mesmo tempo em que há a necessidade de estimulação desse pluralismo teórico, objetivando novas descobertas dos aspectos organizacionais, esse pluralismo provoca uma divisão teórica excessiva, dificultando o entendimento de como as várias escolas de pensamento se relacionam.

As seis teorias mais citadas foram objeto de aprofundamento acerca do seu significado, dada a relevância de seu uso nos anos analisados na área de Estudos Organizacionais (Quadro 2), mas sem a pretensão de se estabelecer um enquadramento das teorias em grupos ou paradigmas clássicos (ver CALDAS; BERTERO, 2007), explorando-as segundo os dados relacionados ao país de origem, natureza do conhecimento (orientação), principais autores e ideias centrais.

Portanto, assemelhando-se aos resultados encontrados por Bertero e Keinert (1994), ao tratar do estudo de avaliação da análise organizacional, a presente investigação assevera que a orientação das teorias aplicadas é multidisciplinar, caracterizando-se pelo predomínio de abordagens sociológicas, econômicas e psicológicas. De acordo com Rodrigues (2000 apud FACHIN; RODRIGUES, 2007, p. 102), os "autores brasileiros têm confiado mais em teorias anglo-saxônicas e têm pouca confiança em conhecimento criado internamente [...]”, sendo que a orientação dos estudos organizacionais brasileiros é moldada, principalmente, pelo pensamento norteamericano ou europeu.

Após a averiguação de todas as teorias citadas no Quadro 2, bem analisando aquelas incluídas na categoria Teorias Diversas, constata-se que, quanto à origem do pensamento, permanece a orientação emprestada de teorias europeias e norteamericanas, fato comprovado por Vergara e 
Pinto (2001) ao analisarem também as referências teóricas em análise organizacional. De acordo com Vergara e Carvalho Jr. (1996 apud FACHIN; RODRIGUES, 2007), a utilização de literaturas estrangeiras pode ser entendida mais pela sua legitimação internacional do que pela sua capacidade de explicação dos fenômenos investigados.

Quadro 2: Síntese das Teorias mais Representativas

\begin{tabular}{|c|c|c|c|c|}
\hline Teoria & Origem & Orientação & $\begin{array}{l}\text { Principais } \\
\text { autores }\end{array}$ & Ideias Centrais \\
\hline $\begin{array}{l}\text { 1. Teoria } \\
\text { Institucional }\end{array}$ & $\begin{array}{l}\text { Estados } \\
\text { Unidos }\end{array}$ & Social & $\begin{array}{c}\text { Anos } 1950 \\
\text { Robert } \\
\text { Merton } \\
\text { Philip } \\
\text { Selznick } \\
\\
\text { Anos 1970- } \\
80 \\
\text { John Meyer } \\
\text { Brian } \\
\text { Rowan } \\
\text { Pamela } \\
\text { Tolbert } \\
\text { Lynne G. } \\
\text { Zucker } \\
\text { Paul } \\
\text { DiMaggio } \\
\text { Walter } \\
\text { Powell }\end{array}$ & $\begin{array}{l}\text { Contrapõe a visão racional- } \\
\text { econômica de Weber; } \\
\text { Explica o comportamento das } \\
\text { organizações e dos indivíduos no } \\
\text { ambiente externo; } \\
\text { As organizações adotam estruturas } \\
\text { internas, políticas e práticas não } \\
\text { porque são necessariamente as } \\
\text { mais eficientes e sim como } \\
\text { resposta a padrões institucionais } \\
\text { que existem fora da organização, } \\
\text { como conjunto de valores, } \\
\text { normas, regras, crenças e verdades } \\
\text { absolutas; } \\
\text { Conceitos principais: Campo } \\
\text { Organizacional, Isomorfismo, } \\
\text { Legitimação. }\end{array}$ \\
\hline $\begin{array}{l}\text { 2. Teoria da } \\
\text { Estruturação }\end{array}$ & $\begin{array}{l}\text { Reino } \\
\text { Unido }\end{array}$ & Social & $\begin{array}{l}\text { Anos 1970- } \\
80 \text { Anthony } \\
\text { Giddens }\end{array}$ & $\begin{array}{l}\text { Não considera que existe } \\
\text { supremacia da estrutura sobre o } \\
\text { indivíduo, entende que ambos se } \\
\text { influenciam mutuamente; } \\
\text { A estruturação constitui-se da } \\
\text { estrutura e da agência (ação } \\
\text { humana); } \\
\text { Conceito principal: "dualidade da } \\
\text { estrutura” }\end{array}$ \\
\hline $\begin{array}{l}\text { 3. Teoria das } \\
\text { Representações } \\
\text { Sociais }\end{array}$ & França & Psicológica & $\begin{array}{l}\text { Anos } 1960 \\
\text { Serge } \\
\text { Moscovici } \\
\text { Anos } 1990 \\
\text { Denise } \\
\text { Jodelet }\end{array}$ & $\begin{array}{l}\text { Rompeu com a dicotomia entre } \\
\text { objetividade e subjetividade, ao } \\
\text { permitir a apreensão dos } \\
\text { fenômenos psicológicos em sua } \\
\text { dimensão social; } \\
\text { Compreensão de um sujeito ou } \\
\text { objeto recriando os significados } \\
\text { com base no que é produzido e } \\
\text { partilhado pelo senso comum; } \\
\text { Considera que as interações entre } \\
\text { os seres sociais constroem } \\
\text { representações de acordo com os } \\
\text { comportamentos, explicações, } \\
\text { crenças e ideias. }\end{array}$ \\
\hline
\end{tabular}




\begin{tabular}{|c|c|c|c|c|}
\hline $\begin{array}{l}\text { 4. Teoria } \\
\text { Crítica }\end{array}$ & Alemanha & Social & $\begin{array}{l}\text { Anos } 1930 \\
\text { Theodor } \\
\text { Adorno } \\
\text { Max } \\
\text { Horkheimer } \\
\\
\text { Anos } 1970 \\
\text { Herbert } \\
\text { Marcuse } \\
\text { Jurgen } \\
\text { Habermas }\end{array}$ & 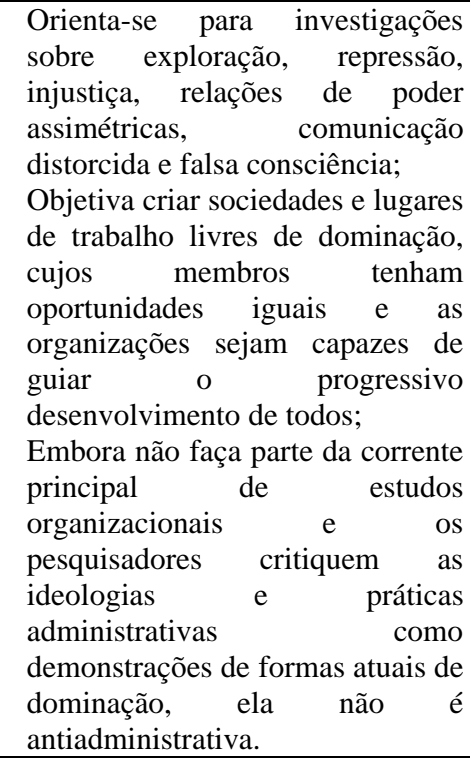 \\
\hline $\begin{array}{l}\text { 5. Teoria da } \\
\text { Agência }\end{array}$ & $\begin{array}{c}\text { Reino } \\
\text { Unido/ } \\
\text { Estados } \\
\text { Unidos }\end{array}$ & Econômica & $\begin{array}{l}\text { Anos } 1770 \\
\text { Adam Smith } \\
\text { Anos } 1930 \\
\text { Adolf A. } \\
\text { Berle } \\
\text { Gardiner C. } \\
\text { Means } \\
\text { Anos } 1970 \\
\text { Michael C. } \\
\text { Jensen } \\
\text { William H. } \\
\text { Meckling }\end{array}$ & $\begin{array}{l}\text { Também chamada de Teoria do } \\
\text { Agente Principal; } \\
\text { Presume a existência de dois } \\
\text { atores: o principal e o agente, } \\
\text { buscando explicar os conflitos de } \\
\text { interesses entre estes e envolve a } \\
\text { delegação de autoridade do } \\
\text { principal para o agente; } \\
\text { O problema surge quando o } \\
\text { agente não atua defendendo o } \\
\text { interesse do principal, ou seja, o } \\
\text { agente age visando a maximizar } \\
\text { seus interesses pessoais; } \\
\text { Lançou as bases da governança } \\
\text { corporativa. }\end{array}$ \\
\hline $\begin{array}{l}\text { 6. Teoria dos } \\
\text { Custos de } \\
\text { Transação }\end{array}$ & $\begin{array}{c}\text { Reino } \\
\text { Unido/ } \\
\text { Estados } \\
\text { Unidos }\end{array}$ & Econômica & $\begin{array}{c}\text { Final dos } \\
\text { anos } 1930 \\
\text { Ronald } \\
\text { Coase } \\
\text { Anos } 1970 \\
\text { Oliver } \\
\text { Williamson }\end{array}$ & $\begin{array}{l}\text { Também conhecida como } \\
\text { Economia dos Custos de Transação } \\
\text { (ECT); } \\
\text { Engloba dois conceitos centrais: a } \\
\text { racionalidade limitada e o } \\
\text { oportunismo dos agentes; } \\
\text { Baseia-se nos custos das transações } \\
\text { entre agentes que são permeadas } \\
\text { por incertezas que levam a firma a } \\
\text { decidir se a produção de } \\
\text { determinado bem deve ser } \\
\text { internalizada ou terceirizada. } \\
\text { Lançou as bases para a defesa da } \\
\text { concorrência e das políticas } \\
\text { antitruste. }\end{array}$ \\
\hline
\end{tabular}

Fonte: Elaborado pelos autores a partir da pesquisa bibliográfica (EnANPAD de 2005-2008). 


\section{CONSIDERAÇÕES FINAIS}

Neste trabalho procurou-se enriquecer o debate acadêmico por meio de uma análise das produções científicas desenvolvidas no contexto brasileiro, identificando a aplicação de teorias para explicação de fenômenos organizacionais, nos quatro anos (2005-2008) de publicações na área temática de Teoria das Organizações do EnANPAD. O presente estudo não pretendeu criticar as teorias utilizadas, nem esgotar o assunto, mas, identificar as correntes teóricas que foram mais aplicadas na área de Estudos Organizacionais.

Dos cento e cinquenta artigos analisados na área temática EOR-A, pouco mais da metade (54,7\%), mencionam teorias clássicas de origem de países da Europa ou dos Estados Unidos e nenhum fomenta o desenvolvimento de novas correntes teóricas no contexto brasileiro. Isto representa certa inércia e uma controvérsia desta área temática, que busca, justamente, fortalecer e explicar os Estudos Organizacionais. Com base nisto, surge um questionamento sobre o enriquecimento da área, já que, se um artigo não contém teoria, ou mesmo se a teoria é fraca ou inadequada, o estudo tem valor considerado suspeito (SUTTON; STAW, 1995). Mesmo assim, quase metade dos artigos (45,3\%) que não se utilizam de teorias foram aprovados por um Encontro de Administração renomado no contexto nacional.

Embora exista um grande número de teorias fundamentando a produção científica dentro do campo de estudos organizacionais, a presente pesquisa constatou a utilização de seis teorias predominantes (Teoria Institucional, da Estruturação, das Representações Sociais, Crítica, da Agência e dos Custos de Transação). As demais teorias encontradas (Teorias Diversas) que embasaram somente três ou menos publicações, evidenciam que, muitas vezes, o debate fica restrito a questões pontuais ou problemas de realidades específicas, não se percebendo a necessidade de continuidade na construção do conhecimento na área e ampliação do campo de estudos. Além disso, a variedade e a dispersão não permitiram, contudo, que se apresentasse uma lista adequada para apresentação neste trabalho, o que poderia representar um maior entendimento teórico, já que a interação entre diferentes perspectivas facilita a compreensão dos fenômenos organizacionais, pois "toda e qualquer escola individual de pensamento oferece, invariavelmente, apenas uma explicação parcial da realidade” (ASTLEY; VAN DE VEN, 2005, p. 53). 
Assim, a aplicação das ideias sociológicas, econômicas e psicológicas no campo de estudos organizacionais demonstra, por um lado, a multidisciplinaridade desta área. Todavia, reflete também por outro lado, o ainda incipiente desenvolvimento de teorias próprias para explicação de fenômenos da área de administração. Outro ponto a ressaltar é a falta de inserção do Brasil como gerador de conhecimento desta área, o que representa uma continuidade da tradição brasileira de importar teorias (FACHIN; RODRIGUES, 2007). Ou seja, apesar de se reconhecer que o uso de uma teoria em diferentes contextos seja uma inovação metodológica, percebe-se ainda que há mais uma replicação de teorias consolidadas internacionalmente do que propriamente uma construção teórica brasileira.

Ademais, foram categorizados o número de autores, a estratégia e a natureza de pesquisa nos artigos analisados. Com base nesses dados, inferiu-se que as publicações são eminentemente colaborativas, com predomínio de dois ou mais autores, representado por $70 \%$ da amostra. Constatou-se que a estratégia de pesquisa é predominantemente qualitativa (91,3\%) e de natureza empírica (65,3\%), levando à conclusão de que os estudos efetuados na área não se valem de técnicas estatísticas para validação dos dados. Bertero, Vasconcelos e Binder (2003) e Hoppen e Meirelles (2005) argumentam que a ampla utilização de métodos qualitativos expressa a fragilidade e a imaturidade do campo de pesquisa em Administração. Isto denota uma carência de métodos mais objetivos, levantando a reflexão sobre a maturidade na área, já que os métodos qualitativos valem-se mais da subjetividade do pesquisador na análise e interpretação dos resultados, o que, para muitos, representa limitações e questionamentos acerca da validade do conhecimento.

Ressalte-se também que, embora tenha sido identificada uma quantidade representativa de artigos teóricos (34,7\%), estes não necessariamente contribuem de forma efetiva para o desenvolvimento de novas teorias e aperfeiçoamento das discussões acerca dos fenômenos organizacionais correntes.

Do ponto de vista acadêmico, esta pesquisa evidencia que a área de estudos organizacionais no Brasil encontra-se permeada de ideias estrangeiras, indicando um tímido desenvolvimento teórico brasileiro. Do ponto de vista prático, demonstra que os fenômenos organizacionais podem ser entendidos sob diversas perspectivas, ampliando a compreensão e estabelecendo direcionamentos para a atividade gerencial nas organizações. 
Como sugestão para estudos futuros, propõe-se a ampliação desta revisão bibliográfica para as demais áreas de Estudos Organizacionais do EnANPAD, bem como a inclusão de outros periódicos científicos brasileiros para averiguar se há equilíbrio entre a aplicação ou não de teorias nos artigos científicos e suas implicações para a compreensão dos fenômenos organizacionais. Não obstante, é necessário refletir e aprofundar a discussão acerca da importância de criar e utilizar teorias como sustentáculo ou tentativa de alterar a práxis organizacional.

\section{REFERÊNCIAS}

ALMEIDA, S. O.; LOPES, T. C.; PEREIRA, R. C. F. A produção científica em marketing de relacionamento no Brasil entre 1990 e 2004. In: II Encontro de Marketing da Anpad - EMA, RJ, 2006, Rio de Janeiro. Anais... Rio de Janeiro: Anpad, 2006.

ANPAD - Associação Nacional dos Programas de Pós-Graduação em Administração. Divisão de artigos de Estudos Organizacionais no Enanpad. Disponível em <http://www.anpad.org.br>. Acesso em: 25/08/2008a.

ANPAD - Associação Nacional dos Programas de Pós-Graduação em Administração. Divisões e Áreas. Disponível em:

$<$ http://www.anpad.org.br/area_popup.php?cod_area_trabalho=127>. Acesso em 25/08/2008b.

ASTLEY, W. G.; VAN DE VEN, A. H. Debates e perspectivas centrais na teoria das organizações. Revista de Administração de Empresas, v. 45, n. 2, p. 52-73, 2005.

BERTERO, C. O.; KEINERT, T. M. M. A evolução da análise organizacional no Brasil (1961-93). Revista de Administração de Empresas, v. 34, n. 3, p. 81-90, 1994.

BERTERO, C. O.; VASCONCELOS, F. C; BINDER, M. P. Estratégia empresarial: a produção científica brasileira entre 1991 e 2002. Revista de Administração de Empresas, v. 43, n.4, p. 48-63, 2003.

BURRELL, G.; MORGAN, G. Sociological Paradigms and Organizational Analysis. Exeter, NH: Heinemann, 1979.

CALDAS, M. P. Paradigmas em estudos organizacionais: uma introdução à série. Revista de Administração de Empresas, v. 45, n. 1, p. 53-57, 2005. 
CALDAS, M. P.; BERTERO, C. O. Teoria das Organizações. São Paulo: Atlas, 2007. 360p.

CALDAS, M. P.; FACHIN, R. Paradigma funcionalista: desenvolvimento de teorias e institucionalismo nos anos 1980 e 1990. Revista de Administração de Empresas, v. 45, n. 2, p. 46-51, 2005.

CARDOSO, R. L.; PEREIRA, C. A.; GUERREIRO, L. Perfil das pesquisas em contabilidade de custos apresentadas no EnANPAD no período de 1998 a 2003. Revista de Administração Contemporânea, v. 11, n. 3, p. 48-63, 2003.

FACHIN, R.; RODRIGUES, S. B. Nota Técnica: Teorizando sobre Organizações - Vaidades ou Pontos de Vista? In: CALDAS, M.; FACHIN, R.; FISCHER, T. Handbook de Estudos Organizacionais. Tradução de: CLEGG, S. R.; HARDY, C.; NORD, W. R. São Paulo: Atlas, 2007.

FARIA, P. C. N.; DE OLIVEIRA, D. F.; LACERDA, T. S; LARA, J. E. Mapeamento, análise e classificação dos trabalhos acadêmicos de marketing nos EnANPADs de 2000 a 2005. In: II Encontro de Marketing da Anpad - EMA, RJ, 2006, Rio de Janeiro. Anais... Rio de Janeiro: Anpad, 2006.

FLICK, U. Uma Introdução à Pesquisa Qualitativa. Porto Alegre: Bookman, 2004.

GRZEBIELUCKAS, C.; CAMPOS, L. M. S.; MARINHO, S. V.; SELIG, P. M. O perfil da produção acadêmica em contabilidade e custos ambientais no período de 1996 a 2007: um estudo bibliométrico. In: XXXII Encontro Nacional dos Programas de Pós-Graduação em Administração - EnANPAD, RJ, 2008, Rio de Janeiro. Anais... Rio de Janeiro: Anpad, 2008.

GUNTHER, H. Pesquisa qualitativa versus pesquisa quantitativa: esta é a questão? Psicologia: Teoria e Pesquisa, v. 22, n. 2, p. 201-210, 2006.

HOPPEN, N.; MEIRELLES, F. S. Sistemas de informação: um panorama da pesquisa científica entre 1990 e 2003. Revista de Administração de Empresas, v. 45, n. 1, p. 24-35, 2005.

KOVACS, M. H.; LEÃO, A. L. M. de S.; VIEIRA, R. S. G.; BARBOSA, L.; DIAS, C. de M. Podemos confiar nos resultados de nossas pesquisas? Uma avaliação dos procedimentos metodológicos nos artigos de 
marketing do EnANPAD. In: I Encontro de Marketing da Anpad - EMA, RS, 2004, Porto Alegre. Anais... Porto Alegre: Anpad, 2004.

LAVILLE, C.; DIONNE, J. A Construção do Saber. Porto Alegre: Artmed, 1997.

MACHADO-DA-SILVA, C. L.; CUNHA, V. C.; AMBONI, N.

Organizações: o estado da arte da produção acadêmica no Brasil. In: XIV Encontro Nacional dos Programas de Pós-Graduação em Administração EnANPAD, SC, 1990, Florianópolis. Anais... Florianópolis: Anpad, 1990.

MALHOTRA, N. Pesquisa de Marketing: Uma Orientação Aplicada. Porto Alegre: Bookman, 2001.

MARCONI, M.; LAKATOS, E. Fundamentos de Metodologia Científica. 6. ed. São Paulo: Atlas, 2006.

RÉVILLION, A. S. P. A Utilização de pesquisas exploratórias na área de marketing. In: XXV Encontro Nacional dos Programas de Pós-Graduação em Administração - EnANPAD, SP, 2001, Campinas. Anais... Campinas: Anpad, 2001.

ROSSONI, L.; GUARIDO FILHO, E. R.; FRANCISCONI, K.; ALBURQUERQUE FILHO, J. B. Estratégia em Organizações: A Produção científica em eventos nacionais entre 2001 e 2006. In: I Encontro de Estudos em Estratégia - 3 E’s, SP, 2007, São Paulo. Anais... São Paulo: Anpad, 2007.

SAMPIERI, R. H.; COLLADO, C. F.; LUCIO, P. B. Metodologia de la Investigación. México: McGraw-Hill, 1994.

SAMPIERI, R. H.; COLLADO, C. F.; LUCIO, P. B. Metodologia de Pesquisa. São Paulo: McGraw-Hill, 2006.

SUTTON, R. I.; STAW, B. M. What theory is not. Administrative Science Quarterly, VYH. 40, n. 3, p. 371-384, 1995.

VERGARA, S. C.; PINTO, M. C. S. Referências teóricas em análise organizacional: um estudo das nacionalidades dos autores referenciados na literatura brasileira. Revista Administração Contemp. [online], v. 5, p. 103-121, 2001.

VIEIRA, F. G. D. Por quem os sinos dobram? Uma análise da publicação científica na área de marketing do EnANPAD. In: XXII Encontro Nacional dos Programas de Pós-Graduação em Administração - 
EnANPAD, PR, 1998, Foz do Iguaçu. Anais... Foz do Iguaçu: Anpad, 1998.

WALTER. S. A.; SILVA, E. D. Visão Baseada em Recursos: um estudo bibliométrico e de redes sociais da produção científica da área de estratégia do EnANPAD 1997-2007. In: XXXII Encontro Nacional dos Programas de Pós-Graduação em Administração - EnANPAD, RJ, 2008, Rio de Janeiro. Anais... Rio de Janeiro: Anpad, 2008.

WHETTEN, D. A. O que constitui uma contribuição teórica? Fórum de Desenvolvimento de Teoria. Revista de Administração de Empresas, v. 43, n. 3, p. 69-73, 2003. 


\section{DAdos dos Autores}

Flavio Perazzo Barbosa Mota (fmota@yahoo.com)

Mestre em Administração pela UFPB

Instituição de vinculação: Universidade Federal da Paraíba

João Pessoa/PB - Brasil

Áreas de interesse em pesquisa: Tecnologia/Sistemas de Informação, Governo Eletrônico, Organizações.

CERES GREHS BECK (ceresbeck@gmail.com)

Mestre em Administração pela UFPB

Instituição de vinculação: Universidade Federal da Paraíba

João Pessoa/PB - Brasil

Áreas de interesse em pesquisa: Marketing, Qualidade, Desenvolvimento Sustentável.

Rita de CÁssia de FARIA Pereira (rita.pereira@pq.cnpq.br)

Doutora em Administração pela UFRGS

Instituição de vinculação: Universidade Federal da Paraíba

João Pessoa/PB - Brasil

Áreas de interesse em pesquisa: Pesquisa e Planejamento de Marketing;

Marketing de Relacionamento e Redes.

Tatiana Aguiar Porfírio de Lima (tatiana.porfirio@yahoo.com.br)

Mestre em Administração pela UFPB

Instituição de vinculação: Universidade Federal da Paraíba

João Pessoa/PB - Brasil

Áreas de interesse em pesquisa: Gestão de Pessoas e Indicadores de Desempenho.

SolAnge CRISTinA do VALE(solange_vale1@yahoo.com)

Mestre em Administração pela UFPB

Instituição de vinculação: Universidade Federal da Paraíba

João Pessoa/PB - Brasil

Áreas de interesse em pesquisa: Organizações e Tecnologia da Informação

Recebido em: 29/10/2009 • Aprovado em: 14/08/2010 